\title{
Semaphorin 3F Induces Colorectal Cancer Cell Chemosensitivity by Promoting P27 Nuclear Export
}

\section{Miaomiao Tao}

Department of Oncology, Fuling Central Hospital of Chongqing City, Chongqing

\section{Hongbo Ma}

Department of Oncology, Fuling Central Hospital of Chongqing City, Chongqing

\section{Xiaoyuan Fu}

Department of Oncology, Fuling Central Hospital of Chongqing City, Chongqing

\section{Cancan Wang}

Department of Oncology, Fuling Central Hospital of Chongqing City, Chongqing

\section{Yanyan Li}

Department of Oncology, Fuling Central Hospital of Chongqing City, Chongqing

Xiaoqiao Hu

Department of Oncology, Fuling Central Hospital of Chongqing City, Chongqing

\section{Renming LV}

Department of Oncology, Fuling Central Hospital of Chongqing City, Chongqing

\section{Gendou Zhou}

Department of Oncology, Fuling Central Hospital of Chongqing City, Chongqing Jun Wang

Department of Oncology, Fuling Central Hospital of Chongqing City, Chongqing

Ruyan Liu

Department of Oncology, Fuling Central Hospital of Chongqing City, Chongqing

\section{Meiyu Zhou}

Department of Oncology, Fuling Central Hospital of Chongqing City, Chongqing

\section{Guofa Xu}

Department of Oncology, Fuling Central Hospital of Chongqing City, Chongqing

\section{Zexin Wang}

Department of Oncology, Fuling Central Hospital of Chongqing City, Chongqing

\section{Xiurong Qin}

Department of Oncology, Fuling Central Hospital of Chongqing City, Chongqing

Yi Long

Department of Oncology, Fuling Central Hospital of Chongqing City, Chongqing

\section{Qunzhen Huang}

Department of Oncology, Fuling Central Hospital of Chongqing City, Chongqing Min Chen 
Department of Oncology, Fuling Central Hospital of Chongqing City, Chongqing

Qi Zhou ( $\square$ qizhou112@163.com )

Department of Oncology, Fuling Central Hospital of Chongqing City, Chongqing

\section{Research Article}

Keywords: Semaphorin 3F, colorectal cancer, chemosensitivity, p27, degradation

Posted Date: January 25th, 2022

DOI: https://doi.org/10.21203/rs.3.rs-1285541/v1

License: (c) (1) This work is licensed under a Creative Commons Attribution 4.0 International License. Read Full License 


\section{Abstract}

Background: Colorectal adenocarcinoma (CRC) is the third most common malignancy worldwide. Metastatic CRC ( $\mathrm{mCRC}$ ) has a poor prognosis and high mortality rate because of chemotherapy resistance, and the overall 5 -year survival rate of $\mathrm{mCRC}$ is only $14 \%$. Our previous study demonstrated that semaphorin $3 \mathrm{~F}$ (SEMA3F) signaling may contribute to reversing chemotherapy resistance in CRC cells by reducing E-cadherin and integrin av $\beta 3$ expression levels. Another study showed that threedimensional (3D) spherical culture of breast cancer cells could upregulate p27 expression and significantly increase the expression of E-cadherin and integrin. This study aimed to evaluate the effect of SEMA3F on P27 and whether it can reverse resistance in CRC cells.

Methods: We compared the chemosensitivity of human colorectal cancer cell lines with different SEMA3F expression levels to 5-Fu through cell experiment and animal experiment. Then the interaction between SEMA3F and p27 and its possible mechanism were explored by Western Blot, immunofluorescence and immunocoprecipitation. We also compared the disease-free survival of $118 \mathrm{CRC}$ patients with high or low expression of SEMA3F.

Results: Overexpresstion of SEMA3F enhanced the chemotherapy sensitivity and apoptosis of CRC cells in vitro. Similar results were also observed in in vivo experiments. Among 118 postoperative mCRC specimens, SEMA3F expression not only enhanced chemotherapy sensitivity but also decreased P27 and multidrug resistance gene expression levels. The disease-free survival of patients with positive SEMA3F expression was significantly longer than that of patients with negative SEMA3F expression after adjuvant treatment. Upregulation of SEMA3F in multicellular spheroid culture (MSC) could increase p27 phosphorylation at serine 10 (Ser10), subsequently promote the cytosolic translocation of P27.

Conclusions: SEMA3F mediates the degradation of p27 and regulates its subcellular localization to enhance chemosensitivity to 5-Fu in CRC cells but does not inhibit p27 expression.

\section{Introduction}

Colorectal adenocarcinoma (CRC) is the third most common malignancy worldwide [1,2], and the prognosis of metastatic CRC ( $\mathrm{mCRC}$ ) remains poor due to chemotherapy resistance. In vivo, solid tumors are three-dimensional (3D) spherical blocks, which depend on cell-cell adhesion and cell-matrix interactions $[3,4]$. In contrast to resistance in two-dimensional (2D) cultures of tumor cells in vitro, multicellular resistance (MCR) in vivo is caused by cell adhesion within tumors to avoid anoikis [5]. Simultaneously, cell-cell contact and extracellular matrix (ECM) attachments prompt tumor cells to enter quiescence or predominantly the $\mathrm{G} 1$ phase of the cell cycle to induce chemotherapy resistance [6-8]. Ecadherin, a member of the classical cadherin family, is widely expressed in epithelial cells, including the cells that make up various types of epithelial cancers [9]. It plays a key role in regulating adhesion in multicellular spheroid cultures (MSCs) of tumor cells [10-12]. p27, a cyclin-dependent kinase inhibitor, is upregulated in multicellular spheroid tumor cells $[13,14]$. Previous studies have demonstrated that 
increased cell-cell adhesion in MSCs affects cell cycle regulation by increasing p27 levels [6,13,14]. Therefore, p27 is a key regulator of contact-dependent growth inhibition that induces cytotoxic drug resistance in multicellular spheroids by increasing E-cadherin and integrin expression.

Previous studies have shown that semaphorin 3F (SEMA3F), a class 3 semaphorin protein, is a suppressor gene located on chromosome 3p21.3 [15]. Many studies have also suggested that SEMA3F, the inhibitory ligand of NRP2, has a repressive effect on growth, angiogenesis, lymphangiogenesis and invasion in several cancers [16-19]. We previously reported that the loss of SEMA3F contributed to CRC cell metastasis [20]. Furthermore, our previous study demonstrated that SEMA3F expression significantly reduced av $\beta 3$ integrin expression in CRC cells to reverse chemotherapy resistance [21]. However, p21 and p27 inhibited anchorage-dependent growth to induce chemotherapy resistance via the upregulation of adhesion molecule expression [6,11,22-24]. VEGF-induced cell cycle progression, including the upregulation of cyclin D1, was reduced by SEMA3A [25], suggesting that SEMA3F may be implicated in cell cycle progression. We thus hypothesize that SEMA3F signaling potently inhibits $\mathrm{p} 27$ to decrease the effects of E-cadherin and integrin and contribute to reversing CRC MCR.

MSC can mimic the anchorage-dependent growth that tumor cells use to survive, display strong adhesion of multicellular spheroids, and can be used to generate powerful in vitro models to perform preclinical chemosensitivity assays [26]. To explore the hypothesis that SEMA3F inhibits $p 27$ to reverse MCR in CRC cells, we analyzed whether SEMA3F plays an underlying role in enhancing multicellular chemosensitivity to 5-Fu in CRC cells. Here, we report that CRC patients with SEMA3F expression exhibited an improved objective clinical response to 5-Fu. Overexpression of SEMA3F induced the apoptosis of CRC cells in MSCs exposed to 5-Fu and chemosensitivity to 5-Fu in transplanted tumors. SEMA3F inhibited tumor cell proliferation and promoted apoptosis by inducing p27 phosphorylation at Ser10 to promote p27 nuclear export. Our findings demonstrate for the first time that SEMA3F plays a novel role and mediates the mechanism of chemosensitivity to 5-Fu in CRC.

\section{Materials And Methods}

\section{Tissue samples}

118 CRC postoperative tissue specimens were collected at Fuling Central Hospital of Chongqing City. All cases were diagnosed by histopathologists according to the Union for International Cancer Control (UICC) classification system. According to the TNM staging criteria for colorectal cancer in the seventh edition of the American Joint Committee (AJCC), all operative patients were defined as stage II to III and had received 5-Fu-based adjuvant chemotherapy for 3-6 months, with an average treatment time of $4.5 \pm 1.5$ months. All CRC patients had received 4 to 6 cycles of 5-Fu combination chemotherapy. tissues were fixed in $10 \%$ formaldehyde and embedded in paraffin for histological sectioning. All human experiments were carried out in accordance with the Declaration of Helsinki (2008) of the World Medical Association and were approved by the Ethics Committee of Fuling Central Hospital of Chongqing City .

\section{Cell culture}


The human colon cancer cell lines HCT-116, LS174T, HT-29, SW480, SW620, LoVo and RKO were obtained from the American Type Culture Collection (ATCC, Manassas, VA) and maintained in L-15 (Invitrogen Corp.) supplemented with $10 \%$ fetal bovine serum at $37^{\circ} \mathrm{C}$ under $5 \% \mathrm{CO}_{2}$. CRC cell spheroids were formed using a 3D culture technique [21]. Briefly, the cells were seeded in 24-well plates coated with $2 \%$ SeaPlaque agarose (BioWhittaker Molecular Applications, Rockland, Maine, USA) at $5 \times 10^{4}$ cells/well in $500 \mu$ l of DMEM.

\section{Antibodies and reagents}

Monoclonal anti-B-cell lymphoma-2 (Bcl-2, \#sc-7382), anti-phospho-Bcl-2-Ser70 (\# sc-293128), anti-BCLXL (\#sc8392), anti-p27 (\#sc-393380), anti-MRP (\#sc-365635), and anti-MCL-1 (\#sc-69840) antibodies were obtained from Santa Cruz Biotechnology (Santa Cruz, CA, USA). Anti-actin antibody (\#sc-8432), used as a control for western blotting (WB), was purchased from Santa Cruz Biotechnology (Heidelberg, Germany). Anti-phospho-Bcl-2-Thr56 (\#2875) was purchased from Cell Signaling Technology (Denver, MA, USA). Anti-phospho-p27-Ser10 antibody (\#346300) was purchased from Invitrogen. Rabbit polyclonal anti-SEMA3F (\#AB5471P) was obtained from Chemicon International (Temecula, USA), and rabbit anti-cleaved Caspase3 (\#9664) and anti-Caspase3 (\#9662) were purchased from Cell Signaling Technology (Boston, MA, USA; 1:100). Anti-kinase-interacting stathmin (KIS) antibody (\#AJ1743c) was obtained from Abgent (San Diego, CA, USA). HRP-conjugated secondary antibodies were purchased from Cell Signaling Technology (Beverly, MA, USA).

\section{Immunohistochemical and immunofluorescence microscopy}

All tissue sections were routinely dewaxed, rehydrated, and prepared for immunohistochemistry. The slides were incubated in $0.3 \% \mathrm{H}_{2} \mathrm{O}_{2}$ in methanol for 30 min to block endogenous peroxidase. Antigens were retrieved with $10 \mathrm{mmol} / \mathrm{L}$ sodium citrate $(\mathrm{pH}=6)$ for $15 \mathrm{~min}$ in a microwave oven. The slides were then incubated with the selected antibody at $37^{\circ} \mathrm{C}$ for $1 \mathrm{~h}$ and at $4{ }^{\circ} \mathrm{C}$ overnight. Slides without primary antibody treatment served as negative controls. The slides were developed with the EnVision ${ }^{\mathrm{TM}}$ method (Dako, Capinteria, CA), visualized using diaminobenzidine solution (Dako, Capinteria, CA) and then lightly counterstained with hematoxylin. Immunohistochemical staining was scored from 0 to 4 as follows: no staining $=0$, weak staining $=1$, strong staining of $25 \%$ or moderate staining of $<80 \%$ of the tumor cells $=$ 2 , strong staining of $25-50 \%$ or moderate staining of $>80 \%$ of the tumor cells $=3$, and strong staining of $>50 \%$ of the tumor cells $=4$. Moreover, samples with a score from 0-1 were defined as negative (recorded as -), and those with a score from 2-4 were defined as positive ( 2 recorded as,+ 3 as,++ 4 as +++ ). Ten representative areas were assessed from high-power fields for each tissue section. The slides were examined and scored independently by 3 pathologists blinded to other patient information.

Samples for immunofluorescence staining were fixed in ice-acetone for 20 min, washed with PBS 3 times for $5 \mathrm{~min}$ each, and incubated for $30 \mathrm{~min}$ at room temperature in a protein-blocking solution. The sections were incubated with the primary antibodies for $1 \mathrm{~h}$ at $37^{\circ} \mathrm{C}$ and then at $4{ }^{\circ} \mathrm{C}$ overnight. After washing, the sections were incubated at $37^{\circ} \mathrm{C}$ for $1 \mathrm{~h}$ with the appropriate secondary antibodies, including FITC- 
conjugated goat anti-rabbit IgG (1:50, Santa Cruz), FITC-conjugated goat anti-mouse IgG (1:50, Santa Cruz), and TRITC-conjugated goat anti-mouse IgG (1:50, Beyotime, China). The sections were counterstained with Hoechst 33258 to reveal the cell nuclei.

\section{Transfection plasmids and establishment of stable cell lines}

The SEMA3F expression vector pSectag-SEMA3F was kindly provided by Dr. David Ginty and used as described previously [18]. SEMA3F RNAi expression vectors and control plasmids were obtained and used as previously described [20]. Small interfering RNAs (siRNAs) against human p27 (\#sc-270646, p27 siRNA: 5'-AAGCACUGCCGAGAUAUGGAAUU-3') and a scrambled siRNA (ctrl_siRNA, 5'AAGACCGAGCCAUUGAGGUAAUU-3') were obtained from Santa Cruz Biotechnology in their deprotected and desalted forms. KIS siRNA and control plasmids were purchased from Sigma-Proligo, and siRNAs against human KIS were obtained from Ambion (Austin, TX) in their deprotected and desalted forms. The chemically synthesized, double-stranded siRNA contained 21-, and vectors containing these sequences were constructed as described previously [22]. All resultant constructs were verified by DNA sequencing and then transfected into target cells with Lipofectamine ${ }^{\mathrm{TM}} 2000$ transfection reagent (Invitrogen, Carlsbad, CA, USA). Transfected cells were enriched by 1 week of antibiotic selection.

\section{Protein extraction and WB}

Cell lysates were prepared with M-PER ${ }^{\mathrm{TM}}$ Mammalian Protein Extraction Reagent (Pierce, PA, USA). Nuclear lysates were prepared with NE-PER ${ }^{\text {TM }}$ Mammalian Protein Extraction Reagent (Pierce, PA, USA). Lysates containing a total of $30 \mu \mathrm{g}$ of protein were separated by SDS-PAGE after heat denaturation, transferred onto PVDF membranes, and incubated with 5\% nonfat milk dissolved in PBS-Tween 20 for $1 \mathrm{~h}$, followed by incubation with a primary antibody overnight at $4{ }^{\circ} \mathrm{C}$. After washing, the membranes were incubated with the appropriate HRP-conjugated secondary antibody and then developed with enhanced chemiluminescence (ECL) detection reagents (Amersham Pharmacia Biosciences).

\section{Coimmunoprecipitation assay}

Total protein lysates $(500 \mu \mathrm{g})$ from each sample were immunoprecipitated in $400 \mu \mathrm{L}$ of lysate buffer containing $2 \mu \mathrm{L}$ of anti-SEMA3F antibody and inhibitors of various proteases, phosphatases and kinases at $4{ }^{\circ} \mathrm{C}$ for $4 \mathrm{~h}$ with rotation. Protein A-conjugated agarose beads $(25 \mu \mathrm{L})$ were then added to the immunoprecipitation reaction and incubated for an additional $5 \mathrm{~h}$ at $4{ }^{\circ} \mathrm{C}$ with rotation. The antigenantibody complexes were precipitated by quick centrifugation, followed by 4 washes with cold PBS. For controls, the immunoprecipitation reaction included an aliquot of rabbit serum instead of the antiSEMA3F antibody. The pellets were suspended in $20 \mu \mathrm{L}$ of $2 \times$ SDS reducing WB loading buffer and boiled for $10 \mathrm{~min}$, followed by SDS-PAGE analysis. The SEMA3F immunoprecipitates were subjected to WB assays to detect SEMA3F and P27 in the immunoprecipitates.

\section{Chemotherapeutics and chemosensitivity assays}


We measured the cytotoxicity of 5-Fu (Adrucil; Pharmacia \& Upjohn, Mississauga, ON, Canada) in tumor spheroid cultures and monolayer cultures. Cells $\left(2 \times 10^{4}\right)$ used for the chemosensitivity assays were seeded into 24-well dishes with $1 \mathrm{~mL}$ of culture medium and divided into monolayer cell cultures (MCs) and MSCs for $48 \mathrm{~h}$ in complete media as described above, after which the chemotherapeutic agent (5-Fu) was added at twice the desired final concentration in $400 \mu \mathrm{mol}$ of complete medium for $48 \mathrm{~h}$. The cells were then harvested, rinsed in PBS to remove residual drug, placed in $0.1 \%$ trypsin-EDTA (Life Technologies, Inc./Invitrogen) in PBS for $10-15 \mathrm{~min}$ at $37^{\circ} \mathrm{C}$ (to disaggregate intact spheroids) and replated as follows: the medium was refreshed with $400 \mu \mathrm{L}$ of 3-(4,5-dimethylthiazol-2-yl)-2,5diphenyltetrazolium bromide (MTT) added to each well at a final concentration of $500 \mu \mathrm{g} / \mathrm{mL}$. After $3 \mathrm{~h}$ of reaction, the reagent was removed, and DMSO was added to dissolve the product. Cell viability was determined by comparing the $\mathrm{OD}_{470}$ value with that of the control group. The experiments were repeated three times. The half-maximal inhibitory concentration (IC50) was defined as the concentration of cisplatin that inhibited cell viability by $50 \%$ and calculated by GraphPad Prism software (version 8.0).

\section{Apoptosis assay}

Immediately following 5-Fu treatment $(100 \mu \mathrm{mol} / \mathrm{L})$ in 3D cultures as described above, the cells were harvested (and then kept on ice), rinsed in PBS, incubated in 0.1\% trypsin-EDTA in PBS for 10-15 min at $37{ }^{\circ} \mathrm{C}$, resuspended in complete medium to inactivate trypsin, rinsed twice in PBS, and fixed in cold buffer for $15 \mathrm{~min}$. The fixed cells were then rinsed twice in buffer and stained with $50 \mu \mathrm{g} / \mathrm{ml}$ propidium iodide (Sigma Chemical Co., Mississauga, ON, Canada) in PBS for 15 min while protected from light and then analyzed using a FACSCalibur analyzer (BD Biosciences, San Jose, CA). The proportion of apoptotic cells was detected by Annexin V/7AAD staining using an Annexin V-PE Apoptosis Detection Kit (BD Biosciences). HT-29 cells in 2D culture were used as the control group. HT-29 cells were plated at a density of $5 \times 10^{4}$ cells/well on 6-well plates and grown overnight. The next day, the cells were treated with 5-Fu $(100 \mu \mathrm{mol} / \mathrm{L})$, and HT-29 cells without 5-Fu treatment were used as the control groups. Each treatment was performed in triplicate, and three different experiments were performed. After $96 \mathrm{~h}$, the cells were harvested, counted, transferred to flow tubes, pelleted, and resuspended in $100 \mu$ lof fresh $1 \mathrm{X}$ Annexin binding buffer (0.01 M HEPES pH 7.4; $\left.0.14 \mathrm{M} \mathrm{NaCl} ; 2.5 \mathrm{mM} \mathrm{CaCl}_{2}\right)$ plus Annexin $\mathrm{V}$ fluorescein isothiocyanate (FITC) and 7-AAD peridinin-chlorophyll protein (PerCP). After staining, the samples were analyzed by flow cytometry within $1 \mathrm{~h}$ using a FACSCanto system (BD). Annexin $\mathrm{V}^{+} / 7 A A D^{ \pm}$cells were considered apoptotic cells. The proportion of apoptotic cells is expressed as a percentage of the total cell number acquired, excluding debris, and was analyzed using BD FACSDiva and FlowJo software (Tree Star, Inc., Ashland, OR, USA).

\section{Animal models}

Four- to six-week-old Balb/c nude mice (body weight: 16-20 g) were purchased from the Experimental Animal Center, Institute of Laboratory Animal Sciences, China, and maintained in a specific pathogen-free (SPF) environment in accordance with the guidelines of the $\mathrm{NIH}$ (Guide for the Care and Use of Laboratory Animals, 1996) [24]. The mice were subcutaneously injected with CRC cells $\left(5 \times 10^{6}\right.$ cells in 
100 uL of PBS/mouse, SEMA3F-overexpressing (SEMA3F OE) LoVo cells for the test groups, LoVo cells for the control groups, 10 nude mice in each group) in the left groin. Two weeks after tumor cell inoculation, animals with tumor sizes reaching approximately $50 \mathrm{~mm}^{3}$ received 5 -Fu at $3 \mathrm{mg} / \mathrm{kg}$ by peritumoral injection every $48 \mathrm{~h}$ for 2 weeks. The mice were sacrificed, and the tumors were collected, half of which were fixed in $4 \%$ formalin and embedded in paraffin blocks. The remaining samples were snapfrozen in liquid nitrogen for histological studies in which five independent fields for each of the three tumors per group were evaluated. All of our animal studies were approved by the Institutional Animal Care and Use Committee of the Fuling Central Hospital, Chongqing. Anesthetic procedures were used, and the animals did not suffer unduly during or after the experimental procedure.

\section{Statistical analyses}

All the data were analyzed using GraphPad Prism software (version 8.0). The immunohistological staining scores were analyzed by 2 biostatisticians in the Department of Statistics at Army Medical University, China. The Kaplan-Meier method and log-rank test were performed for survival analysis. To analyze 5-year disease-free survival (DFS), events were defined as primary local-regional or distant tumor relapse. Descriptive and mean analyses were performed by one-way ANOVA ( $>3$ groups) or Student's $t$ test (between two groups). $P$ values less than 0.05 were considered to indicate significance.

\section{Results}

\section{MSC induced CRC cell chemotherapeutic resistance to 5-Fu in vitro by suppressing SEMA3F}

Several lines of evidence clearly indicate that MSC promotes chemotherapy resistance in tumor cells compared with monolayer cell culture (MC) $[5,10,11,26]$. To demonstrate the ability of MSC to enhance CRC cell resistance to 5-Fu, we investigated the IC50 values of 5-Fu in various CRC cell lines: HCT-116, LS174T, HT-29, SW480, SW620, LoVo and RKO cells (Fig. 1A). Because HT-29 cells expressed SEMA3F and had a low IC50 value in MC (Fig. 1A), we compared the IC50 values of 5-Fu in HT-29 cells in the MSC and MC groups; the IC50 values of 5-Fu in the MSC groups were substantially increased $(P<0.01)$ (Fig. 1B). Compared with those in the MC groups, the cell viabilities in the MSC groups increased significantly after treatment with 5-Fu at different concentrations for $24 \mathrm{~h}(\mathrm{P}<0.01)$ (Fig. 1C). A dose- and timedependent reduction in cell viability was observed following treatment with increasing concentrations of 5-Fu in the MSC and MC groups. The cells were treated with $200 \mu \mathrm{mol} / \mathrm{L}$ 5-Fu, and cell viability was measured at different time points from 6 to $72 \mathrm{~h}$. Similarly, the cell viabilities of the MSC groups were significantly increased at 12,24 and $48 \mathrm{~h}$ compared to those of the $M C$ groups $(P<0.0001)$ (Fig. 1D). These results indicated that MSC resulted in increased 5-Fu resistance in CRC cells.

We then evaluated the effects of MSC on HT-29 cell apoptosis. In MC group, the percentage of apoptotic cells increased after 5-Fu treatment (Fig. 1E, P<0.01), but no similar phenomenon was observed in MSC group, suggesting that MSC resulted in 5-FU resistance. Similarly, the expression of MCL-1, an antiapoptotic gene, was significantly higher in the MSC groups than in the MC groups (Fig. 1F). In addition, 
the phosphorylation of BCL-2 at threonine 56 (phospho-Bcl-2-Thr56) in the two groups was no different, but the phosphorylation of BCL-2 at serine 70 (phospho-Bcl-2-Ser70) was decreased in the MSC groups. After 5-Fu chemotherapy, the phosphorylation of BCL-2 at both the Thr56 and Ser70 sites was increased, but there was no difference between the two groups (Fig. 1F). Furthermore, regardless of whether chemotherapy had been applied, the expression of cleaved caspase 3 in the MSC groups was significantly lower than that in the MC groups (Fig. 1F). These results showed that SEMA3F expression may restore the chemotherapeutic sensitivity of CRC cells to 5-Fu. Then, we compared the expression of SEMA3F in $\mathrm{HT}-29$ cells between the MSC and MC groups and found that SEMA3F expression was significantly decreased in the MSC groups (Fig. 1G). These data suggested that MSC-induced chemotherapy resistance in CRC cells was probably due to the inhibition of SEMAF expression.

\section{SEMA3F improved the chemotherapeutic response of CRC cells to 5-Fu in vitro}

We further examined the effects of SEMA3F on the response of CRC cells to 5-Fu. Since the HT-29 and LS174T cell lines tend form multicellular spheroids in 3D culture, and the IC50 value of 5-Fu in HT-29 cells was low while in LS174T cells was the highest, we chose these two cell lines for subsequent experiments. SEMA3F expression in the HT-29 and LS174T cell lines was knocked down, and the IC50 values of 5-Fu in the cells grown under MSC conditions and treated with 5-Fu were compared. We found that the IC50 values of the SEMA3F KD groups were higher than those of the control groups $(P<0.05$; Fig. 2A, $B, E$ and $\mathrm{F})$. As the 5-Fu concentration increased and the treatment time was prolonged, the cell activity decreased gradually, but the activity of the SEMA3F KD groups was always higher than that of the control groups $(P<0.05$; Fig. $2 C, D, G$ and $H)$. These results suggested that $C R C$ cells were more resistant to 5 -Fu when SEMA3F was knocked down. In contrast, when SEMA3F was overexpressed in LoVo cells (the transplanted tumor animal model was easy to successfully generate using LoVo cells) and the cells were treated with 5-Fu (Fig. 2I), the IC50 value of 5-Fu of the SEMA3F OE group was decreased compared with that of the control group $(P<0.05$,Fig. $2 \mathrm{~J})$. In addition, the cell viability of the SEMA3F OE group was always lower than that of the control group, although a dose- and time-dependent reduction in cell viability was observed following treatment with 5-Fu (Fig. 2K, L). These data demonstrated that SEMA3F activity enhanced the chemotherapeutic response of CRC cells to 5-Fu in vitro.

\section{SEMA3F overexpression enhanced the sensitivity of CRC cells to 5-Fu in vivo}

To explore whether changes in SEMA3F expression could influence the sensitivity of CRC cells to 5-Fu in vitro, we injected SEMA3F OE LoVo cells into the left groin of nude mice and then treated them with 5-Fu or PBS. Mice treated with LoVo cells were used as the control groups. With prolonged time, the volume of the tumor xenografts increased gradually but was reduced after treatment with 5 -Fu in both groups. The volume and weight of the xenograft tumors in the SEMA3F OE groups were significantly lower than those in the control groups, and further reduced after treatment with 5-Fu (Fig. 3A-C, $P<0.05)$. Similarly, cleaved caspase3 tissue expression in the SEMA3F OE group significantly increased with 5-Fu treatment.

Regardless of whether 5-Fu treatment was applied, there was no difference in the expression of cleaved 
caspase3 in the control group (Fig. 3D,E). Consequently, these consistent data suggest that SEMA3F enhanced the sensitivity of CRC cells to 5 -Fu and promoted apoptosis in vivo.

\section{SEMA3F enhances the sensitivity of CRC cells to 5-Fu by downregulating p27activity}

Our previous study demonstrated that SEMA3F signaling significantly reduced aV $\beta 3$ integrin expression to prevent chemotherapy resistance in CRC cells [21], and other studies have reported that p27 plays an important role in inducing drug resistance by increasing the expression of E-cadherin and integrin $[7,12]$. Thus, we investigated whether SEMA3F enhanced the sensitivity of CRC cells to 5-Fu by downregulating p27 expression. We compared the nuclear protein expression of p27 and multidrug resistance-associated protein (MRP) in SEMA3F OE and control LoVo cells under MSC. Significantly reduced nuclear expression of the 27 and MRP proteins was observed in the SEMA3F OE groups (Fig. 4A). In CRC patient samples, SEMA3F expression was positive in chemotherapy-sensitive tissues while negative in chemotherapyresistant samples, as shown by immunohistochemical staining. Moreover, the expression level of SEMA3F was negatively correlated with the expression of P27 and MRP (Fig. 4B). We next asked whether we could enhance chemotherapy sensitivity by knocking down P27 expression in CRC cells. Thus, we employed p27-knockdown LoVo cells treated with 5-Fu and found that their cellular viability was not reduced upon 5-Fu treatment. Interestingly, P27 knockdown in LoVo cells did not decrease cellular viability with 5-Fu treatment; only in SEMA3F OE cells without P27 silencing was cellular viability significantly decreased (Fig. 4C,D). Overall, these results demonstrated that SEMA3F did not enhance the sensitivity of CRC cells to 5-Fu when p27 expression was completely absent. It may be that the complete blockade of P27 expression caused the CRC cells to proliferate too fast. SEMA3F might enhance the chemotherapeutic sensitivity of CRC cells to 5-Fu by partially downregulating p27 activity.

\section{SEMA3F promotes p27 degradation by interacting with $p 27$ and inducing p27 phosphorylation at Ser10}

To explore the underlying interaction between SEMA3F and p27, we overexpressed SEMA3F in CRC cells under MSC conditions and employed these cells as a model to determine the interaction between SEMA3F and p27 using immunofluorescence analysis and immunoprecipitation. Immunofluorescence analysis showed that the expression of SEMA3F was negatively correlated with the nuclear expression of P27 (Fig. 5A). Interestingly, p27 was primarily localized in the cytoplasm, not the nucleus. This finding may explain the ability of SEMA3F to downregulate P27 nuclear expression. Furthermore, the coimmunoprecipitation results suggested an interaction between SEMA3F and p27 (Fig. 5B). Additionally, it was previously confirmed that p27 is phosphorylated much earlier at Ser10 than at other phosphorylation sites; this process is required for p27 nuclear export and accounts for approximately $70 \%$ of the total phosphorylation of this protein [27-29]. Therefore, we measured the phosphorylation of p27 at Ser10 when SEMA3F was overexpressed. We found that along with SEMA3F expression, the phosphorylation of p27 at Ser10 was increased (Fig. 5C). Human KIS (hKIS) has been shown to mediate the phosphorylation of p27 at Ser10 [30]. Thus, we measured the change in p27 at different SEMA3F expression levels when hKIS was knocked down in CRC cells under MSC conditions. The p27 expression level in the nucleus was on different in the control and SEMA3F OE groups. However, when hKIS 
expression was normal, p27 nuclear expression was decreased in the SEMA3F OE groups compared with the control groups (Fig. 5D). These results indicate that SEMA3F promotes $\mathrm{p} 27$ phosphorylation at Ser10 to degrade 27 and decrease its nuclear export.

\section{CRC patients with high SEMA3F expression are more sensitive to 5-Fu chemotherapy than those with low SEMA3F expression}

We further confirmed the above findings in CRC patients. The expression of SEMA3F was detected by immunohistochemistry in postoperative tissue samples from patients with recurrent and nonrecurrent CRC who received adjuvant chemotherapy and were followed up for six years. All patients had received 5Fu-based adjuvant chemotherapy for 3 to 6 months, with an average treatment time of $4.5 \pm 1.5$ months. Because adjuvant chemotherapy for colon cancer is 5-Fu monotherapy or 5-Fu plus oxaliplatin (based on the patient's postoperative staging status), the chemotherapy regimen was consistent and not subject to interference by irinotecan, antiangiogenic therapy, or molecular targeted therapy. The results showed that SEMA3F staining was significantly stronger in the tissue samples from patients with nonrecurrent CRC than in those from patients with recurrent CRC (Fig. 6A). The SEMA3F expression index was markedly higher in the group without recurrence than in the recurrence group (Fig. 6B). Furthermore, SEMA3F expression was detected in tissue samples from the group without recurrence, and the majority of the samples (56/67) were strongly positive (++ ++++). However, most of the recurrent tissue samples $(46 / 51)$ were negative(-) or weakly positive(+) (Fig. 6C). Subsequently, we explored the prognostic value of SEMA3F in CRC patients. We followed up $118 \mathrm{CRC}$ patients after chemotherapy including 5-Fu for six years. The median DFS of the low SEMA3F expression group was only 38 months, but the median DFS of the high SEMA3F expression group was still undefined (HR=0.28, 95\% Cl: 0.14-0.56, $\mathrm{P}=0.0001$, Fig. 6D). The above results suggested that CRC patients with high SEMA3F expression are more sensitive to 5-Fu chemotherapy than those with low SEMA3F expression.

\section{Discussion}

In this study, we found that SEMA3F expression was downregulated and that the IC50 value of 5-Fu in CRC cells was substantially increased in the MSC groups. Our previous study demonstrated that SEMA3F expression significantly reduced $a_{\mathrm{V}} \beta_{3}$ integrin expression levels in CRC cells to block chemotherapy resistance [21]. Hence, we believe that SEMA3F may prevent tumor microenvironment-mediated MCR.

p27 plays an important role in inducing chemotherapy resistance in multicellular spheroids by increasing E-cadherin and integrin expression levels. Previous studies on tumor multicellular drug resistance have mainly focused on enhanced cell adhesion, resulting in decreased penetration of chemotherapeutic drugs and the entrance of tumor cells into a quiescent state. When HT29 human colorectal cancer cells converged, the expression of p27 increased, and the cells accumulated in the G0/G1 phase of the cell cycle. Nonfused HT29 cells overexpressing p27 were also more resistant to anticancer drugs [31]. However, this study did not use a multicellular spheroid model. The core area of HCT116 multicellular spheroids was negative for the proliferation marker Ki67 but positive for $\mathrm{p} 27$. One possible mechanism 
for the upregulation of p27 is downregulation of the ERK signal, which is observed in multicellular spheroids [32]. Our research focuses on how the SEMA3F signal inhibits P27 function to reverse tumor multicellular drug resistance and its mechanism. In this study, we upregulated SEMA3F expression in vitro and observed increased sensitivity to 5-Fu in CRC cells in the MSC groups; the same result was found in vivo, and CRC cell apoptosis was induced. When we overexpressed SEMA3F in CRC cells, CRC multicellular spheroids showed significantly decreased p27 nucleoprotein expression and increased chemosensitivity. Interestingly, we found that P27 knockdown did not affect the response of the CRC cells under MSC to 5-Fu, and only SEMA3F OE cells without P27 silencing exhibited increased chemosensitivity. It may be that the complete blockade of P27 expression caused the CRC cells to proliferate too fast. This phenomenon is consistent with the clinical treatment of refractory lymphoma with high proliferative activity [33]. This indicates that SEMA3F might enhance the chemotherapeutic sensitivity of CRC cells to 5-Fu by partially downregulating p27 activity. In 5-Fu-sensitive CRC patient samples, we found that p27 and MRP were barely detected, whereas SEMA3F was highly expressed. The molecular mechanism by which SEMA3F signals reverse MCR in CRC cells remains unknown.

Moreover, when we upregulated SEMA3F expression in CRC cells, p27 was primarily localized in the cytoplasm but not in the nucleus. These data implied that SEMA3F prevents the nuclear localization of p27 to promote cell cycle progression. How does SEMA3F induce p27 cytoplasmic translocation? We found that SEMA3F stimulates the phosphorylation of p27 at Ser10. Several previous studies have shown that the phosphorylation of p27 at Ser10 induces its export to the cytoplasm and promotes its degradation at G1 phase [34,35]. These results indicated that SEMA3F promoted p27 phosphorylation at

Ser10, leading to its export from the nucleus to the cytoplasm. They also suggested that SEMA3F increased p27 degradation, rather than its proteolysis, to induce tumor cells to enter the cell cycle. These results reveal for the first time that SEMA3F mediates $\mathrm{p} 27$ degradation by inducing $\mathrm{p} 27$ phosphorylation at Ser10.

How does SEMA3F, as a secretory protein, affect signals in the nucleus? In a study of neural development, SEMA3A was found to inhibit the growth of axonal growth cones through the phosphorylation of CDK-5 and glycogen synthase kinase-3 (GSK3) [36]. SEMA3A and SEMA3F can also suppress rapamycin complex (mTORC) signaling [37,38]. Secreted proteins have also been suggested to affect intracellular signals. Recently, it has been reported that retinoic acid receptor-related orphan receptor a (ROR a) [39], Achaete scute-like 2 (ASCL2) [40] and DNA inhibitor binding/differentiation 2 (Id2) [41] bind the promoter region of SEMA3F in colon cancer. These three transcription factors promote or inhibit SEMA3F transcription to affect its expression. In this study, SEMA3F was found to cause the cytoplasmic translocation of P27. However, whether cytoplasmic P27 translocation is caused by unsecreted SEMA3F in the cytoplasm needs to be further studied.

\section{Conclusion}

In conclusion, our data show that SEMA3F reverses CRC cell and patient chemotherapy resistance by inducing the phosphorylation of p27 at Ser10 to modulate the subcellular localization of p27. Our 
findings present a novel mechanism underlying the role of SEMA3F in the chemosensitivity of CRC cells and suggest a potential therapeutic strategy for CRC.

\section{Abbreviations}

SEMA3F: Semaphorin 3F; CRC: colorectal adenocarcinoma; ; ECM: extracellular matrix; MSC: multicellular spheroid culture; MC: monolayer cell culture; SEMA3F KD: SEMA3F knockdown; SEMA3F OE: SEMA3F overexpression; 5-Fu: 5-fluorouracil; hKIS: human kinase-interacting stathmin; DFS: disease-free survival; MCR: multicellular resistance.

\section{Declarations}

\section{Ethical approval and consent to participate}

All studies involving human samples were approved by Fuling Central Hospital of Chongqing City. All animal studies were approved by the Animal Care and Use Committee of Fuling Central Hospital of Chongqing City, China.

\section{Consent for publication}

Not applicable.

\section{Availability of data and materials}

The datasets used or analysed during the current study are available from the corresponding author on reasonable request.

\section{Competing interests}

The authors declare that they have no competing interests.

\section{Funding}

This work was supported by grant number cstc2019jcyj-msxmX0711 from the Natural Science Foundation of Chongqing Municipal Science and Technology Commission (to Q.Z.) and grant number ZY201802003 from the Chongqing medical scientific research project (Joint project of Chongqing Health Commission and Science and Technology Bureau)(to M.T.).

\section{Author contributions}

M.C and Q.Z designed the study. Q.Z, M.T and H.M prepared the figures and wrote the article. M.T and H.M performed all of the gene transfection experiments, Western blotting, and data analysis. X.Fu and C.W generated the CRC cell multicellular spheroid cultures and monolayer cell clusters and carried out gene knockout. Y.L, X.H and X.Q performed the immunohistochemical and immunofluorescence assays. 
R.L and G.Z performed the flow cytometry and apoptosis assays. J.W and M.Z performed the chemotherapeutic and chemosensitivity assays. G.X performed the coimmunoprecipitation assays. Q.H and Y.L performed the animal experiments. Z.W provided valuable recommendations, contributing to the study design and data analysis. R.L performed the follow-up.

\section{Acknowledgments}

We would like to thank the referees and editor, who provided outstanding advice and helped us build the concepts presented in this work. We thank Dr. Juanjuan Ou, Department of Oncology, Southwest Hospital, Army Medical University, Chongqing, China, for her excellent technical assistance and help in editing this manuscript. The authors thank Dr. Feng Wu, Institute of Pathology of Army Medical University, for help in editing this manuscript. We thank Wei Sun of the Central Laboratory of Army Medical University for her excellent technical assistance in confocal laser scanning microscopy.

\section{References}

[1] Siegel RL, Miller KD, Jemal A.Cancer statistics, 2019. CA Cancer J Clin. 2019,69(1): 7-34.

[2] Siegel RL, Miller KD, Fedewa SA, Ahnen DJ, Meester RGS, Barzi A, Jemal A. Colorectal cancer statistics, 2017.CA Cancer J Clin.2017,67(3):177-93.

[3] Labernadie A, Kato T, Brugués A, Serra-Picamal X, Derzsi S, Arwert E, Weston A, González-Tarragó V, Elosegui-Artola A, Albertazzi L, et al: A mechanically active heterotypic E-cadherin/N-cadherin adhesion enables fibroblasts to drive cancer cell invasion. Nat Cell Biol. 2017;19(3):224-37.

[4] Dong Y, Tan OL, Loessner D, Stephens C, Walpole C, Boyle GM, Parsons PG, Clements JA. Kallikreinrelated peptidase 7 promotes multicellular aggregation via the alpha(5)beta(1) integrin pathway and paclitaxel chemoresistance in serous epithelial ovarian carcinoma.Cancer Res. 2010;70(7):2624-33.

[5] Kang HG, Jenabi JM, Zhang J, Keshelava N, Shimada H, May WA, Ng T, Reynolds CP, Triche TJ, Sorensen PH.E-cadherin cell-cell adhesion in ewing tumor cells mediates suppression of anoikis through activation of the ErbB4 tyrosine kinase.Cancer Res. 2007 ;67(7):3094-105.

[6] Seifert A, Posern A.Tightly controlled MRTF-A activity regulates epithelial differentiation during formation of mammary acini. Breast Cancer Res.2017,19(1):68.

[7] Tsytlonok M, Sanabria H, Wang Y, Felekyan S, Hemmen K, Phillips AH, Yun MK, Waddell MB, Park CG, Vaithiyalingam S,Iconaru L, White S W, Tompa P, Seidel CA, Kriwacki R. Dynamic anticipation by Cdk2/Cyclin A-bound p27 mediates signal integration in cell cycle regulation.Nat Commun.2019,10(1):1676.

[8] Derksen PW, Liu X, Saridin F, Gulden H, Zevenhoven J, Evers B, Beijnum JR, Griffioen AW, Vink J, Krimpenfort P, Peterse JL, Cardiff RD, Berns A, Jonkers J. Somatic inactivation of E-cadherin and p53 in 
mice leads to metastatic lobular mammary carcinoma through induction of anoikis resistance and angiogenesis. Cancer Cell.2006;10(5): 437-49.

[9] Bi E, Li R, Bover LC, Li H, Su P, Ma X, Huang C, Wang Q, Liu L, Yang M, Lin Z, Qian J, Fu W, Liu YJ, Yi Q.E-cadherin expression on multiple myeloma cells activates tumor-promoting properties in plasmacytoid DCs. J Clin Invest. 2018;128(11):4821-31.

[10] Galateanu B, Hudita A, Negrei C, lon RM, Costache M, Stan M, Nikitovic D, Hayes AW,

Spandidos DA, Tsatsakis AM, Ginghina O. Impact of multicellular tumor spheroids as an in vivo like tumor model on anticancer drug response. Int J Oncol. 2016;48(6):2295-302.

[11] LaRue KE, Khalil M, Freyer JP. Microenvironmental regulation of proliferation in multicellular spheroids is mediated through differential expression of cyclin-dependent kinase inhibitors. Cancer Res. 2004; 64(5):1621-31.

[12] Das RK, Huang Y, Phillips AH, Kriwacki RW, Pappu RV. Cryptic sequence features within the disordered protein p27Kip1 regulate cell cycle signaling. Proc Natl Acad Sci U S A.2016,

113(20):5616-21.

[13] Carduner L, Picot CR, Leroy-Dudal J, Blay L, Kellouche S, Carreiras F. Cell cycle arrest or survival signaling through av integrins, activation of PKC and ERK1/2 lead to anoikis resistance of ovarian cancer spheroids. Exp Cell Res. 2014;320(2):329-42.

[14] Liu Y,Lv J,Liang X,Yin X,Zhang L,Chen D,Jin X,Fiskesund R,Tang K,Ma J,et al:Fibrin Stiffness Mediates Dormancy of Tumor-Repopulating Cells via a Cdc42-Driven Tet2 Epigenetic Program.Cancer Res.2018,78(14):3926-37.

[15] Doçi CL, Mikelis CM, Lionakis MS, Molinolo AA, Gutkind JS.Genetic Identification of SEMA3F as an Antilymphangiogenic Metastasis Suppressor Gene in Head and Neck Squamous Carcinoma.Cancer Res. 2015;75(14):2937-48.

[16] Bollard J, Massoma P, Vercherat C, Blanc M, Lepinasse F, Gadot N, Couderc C, Poncet G, Walter T, Joly MO, Hervieu V, Scoazec JY, Roche C.The axon guidance molecule

semaphorin $3 \mathrm{~F}$ is a negative regulator of tumor progression and proliferation in ileal neuroendocrine tumors.Oncotarget. 2015;6(34):36731-45.

[17] Ou JJ, Wei X, Peng Y, Zha L, Zhou RB, Shi H, Zhou Q, Liang HJ.Neuropilin-2 mediates lymphangiogenesis of colorectal carcinoma via a VEGFC/VEGFR3 independent signaling. Cancer Lett. 2015;358(2):200-09. 
[18] Bielenberg DR, Hida Y, Shimizu A, Kaipainen A, Kreuter M, Kim CC, Klagsbrun M. Semaphorin 3F, a chemorepulsant for endothelial cells, induces a poorly vascularized, encapsulated, nonmetastatic tumor phenotype. J Clin Invest. 2004;114(9):1260-71.

[19] Futamura M, Kamino H, Miyamoto Y, Kitamura N, Nakamura Y, Ohnishi S, Masuda Y, Arakawa H.Possible role of semaphorin 3F, a candidate tumor suppressor gene at 3p21.3, in p53-regulated tumor angiogenesis suppression.Cancer Res. 2007;67(4):1451-60.

[20]Wu F, Zhou Q, Yang J, Duan GJ, Ou JJ, Zhang R, Pan F, Peng QP, Tan H, Ping YF, Cui Y, Qian C, Yan $X$, Bian $X$. Endogenous axon guiding chemorepulsant semaphorin-3F inhibits the growth and metastasis of colorectal carcinoma. Clin Cancer Res. 2011;17(9):2702-11.

[21] Zheng C, Zhou Q, Wu F, Peng Q, Tang A, Liang H, Zeng Y.Semaphorin3F down-regulates the expression of integrin alpha(v)beta3 and sensitizes multicellular tumor spheroids to chemotherapy via the neuropilin-2 receptor in vitro. Chemotherapy. 2009;55(5):344-52.

[22] Jolly MK, Ware KE, Xu, S. E-Cadherin Represses Anchorage-Independent Growth in Sarcomas through Both Signaling and Mechanical Mechanisms.Mol Cancer Res. 2019 ;17(6):1391-402.

[23] Nasarre P, Kusy S, Constantin B, Castellani V, Drabkin HA, Bagnard D, Roche J.

Semaphorin SEMA3F has a repulsing activity on breast cancer cells and inhibits E-cadherin-mediated cell adhesion. Neoplasia. 2005;7(2):180-9.

[24] Bahnassy AA,Helal TE,El-Ghazawy IM, Samaan GF, Galal El-Din MM, Abdellateif MS, Desouky E, Zekri AN.The role of E-cadherin and Runx3 in Helicobacter Pylori - Associated gastric carcinoma is achieved through regulating P21 waf and P27 expression.Cancer Genet. 2018,228-229:64-72.

[25] Catalano A, Caprari P, Rodilossi S, Betta P, Castellucci M, Casazza A, Tamagnone L, Procopio A.Crosstalk between vascular endothelial growth factor and semaphorin-3A pathway in the regulation of normal and malgnant mesothelial cell proliferation. FASEB J.2004;18:358-60.

[26] Powan P, Luanpitpong S, He X, Rojanasakul Y, Chanvorachote P.Detachment-induced E-cadherin expression promotes 3D tumor spheroid formation but inhibits tumor formation and metastasis of lung cancer cells.Am J Physiol Cell Physiol.2017,313(5):C556-C566.

[27] Hnit SS, Xie C, Yao M, Holst J, Bensoussan A, De Souza P, Li Z, Dong Q.p27(Kip1) signaling: Transcriptional and post-translational regulation. Int J Biochem Cell Biol.2015,68:9-14.

[28] Li Y, Nakka M, Kelly AJ, Lau CC, Krailo M, Barkauskas DA, Hicks JM, Man TK.p27 Is a Candidate Prognostic Biomarker and Metastatic Promoter in Osteosarcoma. Cancer Res.2016,76(13):4002-11.

[29] Yoon H,Kim H,Jan K,Shin M,Besser A,Xiao X,Zhao D,Wander SA,Briegel K, Morey L,Minn A, Slingerland JM.p27 transcriptionally coregulates c-Jun to drive programs of tumor 
progression.Proc Natl Acad Sci U S A.2019,116(14):7005-14.

[30] Wang HC, Lee WS.Molecular mechanisms underlying progesteroneinduced cytoplasmic retention of p27 in breastcancer cells. J Steroid Biochem Mol Biol.2018,183:202-09.

[31] Dimanche-Boitrel MT, Micheau O, Hammann A, Haugg M, Eymin B, Chauffert B, Solary E:Contribution of the cyclin-dependent kinase inhibitor p27KIP1 to the confluence-dependent resistance of HT29 human colon carcinoma cells. Int J Cancer. 77:796-802,1998

[32] Zhang X,de Milito A,Olofsson MH,Gullbo J,D'Arcy P,Linder S:Targeting Mitochondrial Function to Treat Quiescent Tumor Cells in Solid Tumors Int J Mol Sci. 16:27313-27326,2015.

[33] Sehn LH,Herrera AF,Flowers CR,Kamdar MK,McMillan A,Hertzberg M,Assouline S, Kim TM,Kim WS,Ozcan M,et al: Polatuzumab Vedotin in Relapsed or Refractory Diffuse Large B-Cell Lymphoma. J Clin Oncol. 38: 155-165, 2020

[34] Théard D, Raspe MA, Kalicharan D, Hoekstra D, van IJzendoorn SC. Formation of E-cadherin/betacatenin-based adherens junctions in hepatocytes requires serine-10 in p27(Kip1). Mol Biol Cell. 2008 ,19(4):1605-13.

[35] Li Z, Tao Y, Wang X, Jiang P, Li J, Peng M, Zhang X, Chen K, Liu H, Zhen P,Zhu J, Liu X, Liu X.TumorSecreted Exosomal miR-222 Promotes Tumor Progression via Regulating P27 Expression and ReLocalization in Pancreatic Cancer.Cell Physiol Biochem.2018,51(2):610-29.

[36] Perlini LE, Szczurkowska J, Ballif BA, Piccini A, Sacchetti S, Giovedì S, Benfenati F, Laura Cancedda L.Synapsin III Acts Downstream of Semaphorin 3A/CDK5 Signaling to Regulate Radial Migration and Orientation of Pyramidal Neurons In Vivo. Cell Rep. 2015;11(2):234-48.

[37] Nakayama H, Bruneau S, Kochupurakkal N, Coma S, Briscoe DM, Klagsbrun Regulation of mTOR Signaling by Semaphorin 3F-Neuropilin 2 Interactions In Vitro and In Vivo. Sci Rep.2015;5:11789.

[38] Yamada D, Kawahara K, Maeda mTORC1 is a critical mediator of oncogenic Semaphorin3A signaling. Biochem Biophys Res Commun. 2016;476(4):475-480.

[39] Xiong G, Wang C, Evers BM,Zhou BP, Xu R. RORa suppresses breast tumor invasion by inducing SEMA3F expression. Cancer Res 2012; 72:1728-1739.

[40] Zhou ZH, Rao J,Yang J,Wu F,Tan J,Xu SL,Ding YQ,Zhan N,Hu XG,Cui YH,Zhang X, Dong WG, Liu XD,Bian XW.SEMA3F prevents metastasis of colorectal cancer by PI3K-AKT-dependent down-regulation of the ASCL2-CXCR4 axis. J Pathol 2015; 236: 467-478.

[41] Coma S, Amin DN, Shimizu A, Lasorella A, lavarone A, Klagsbrun M. Id2 promotes tumor cell migration and invasion through transcriptional repression of semaphorin3F. Cancer Res 2010; 70: 38233832 . 
A

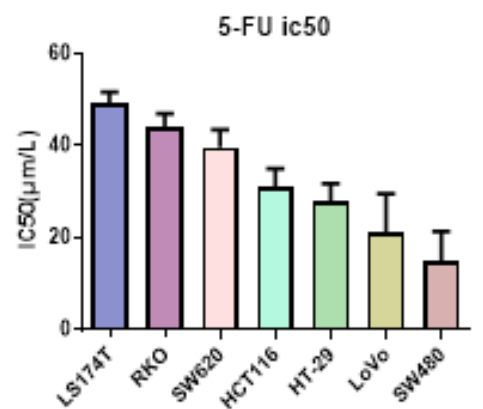

$\mathbf{E}$
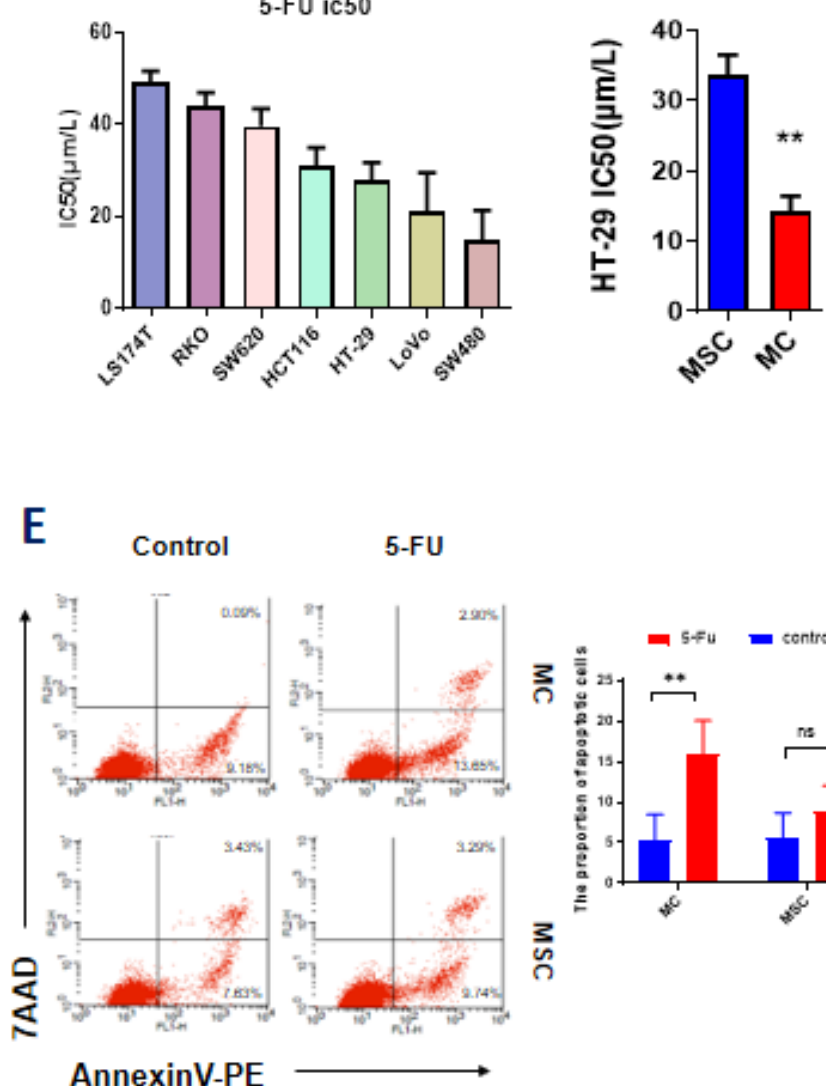

B

C
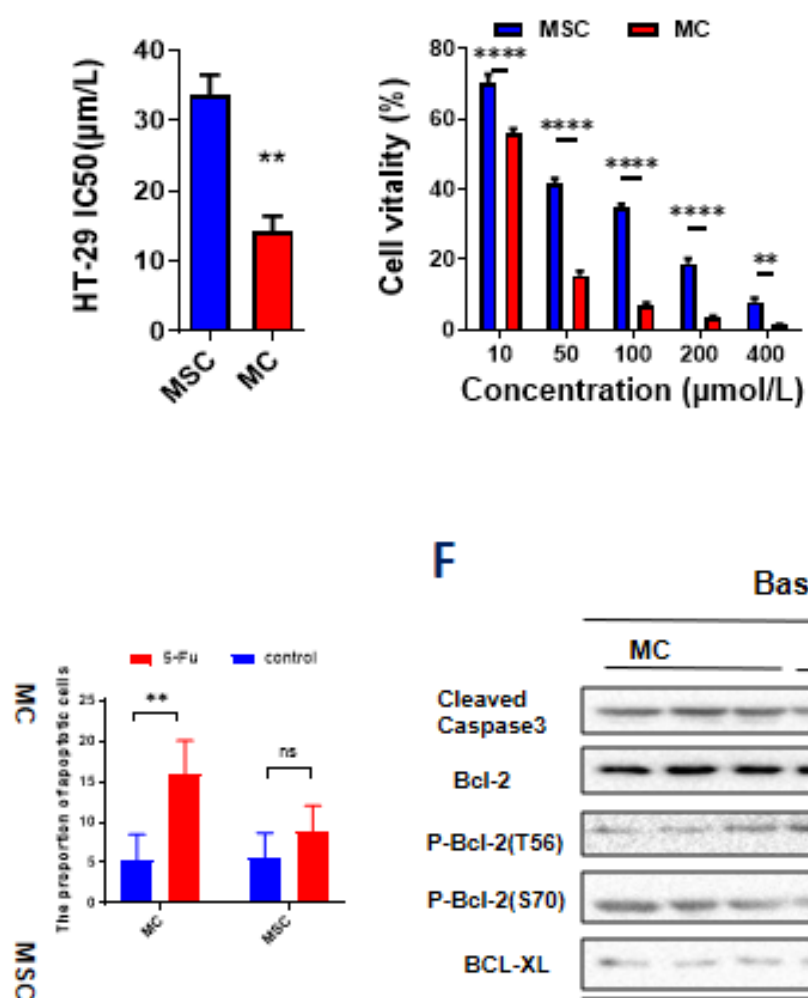

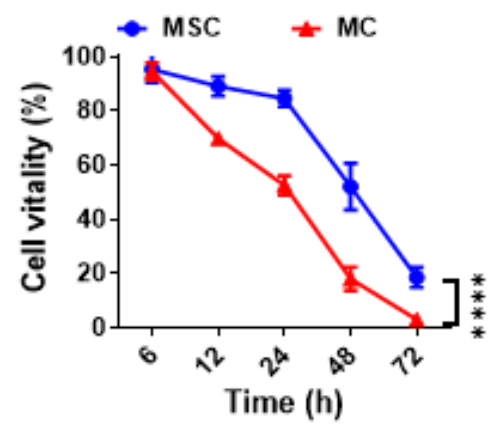

$\mathbf{F}$

D

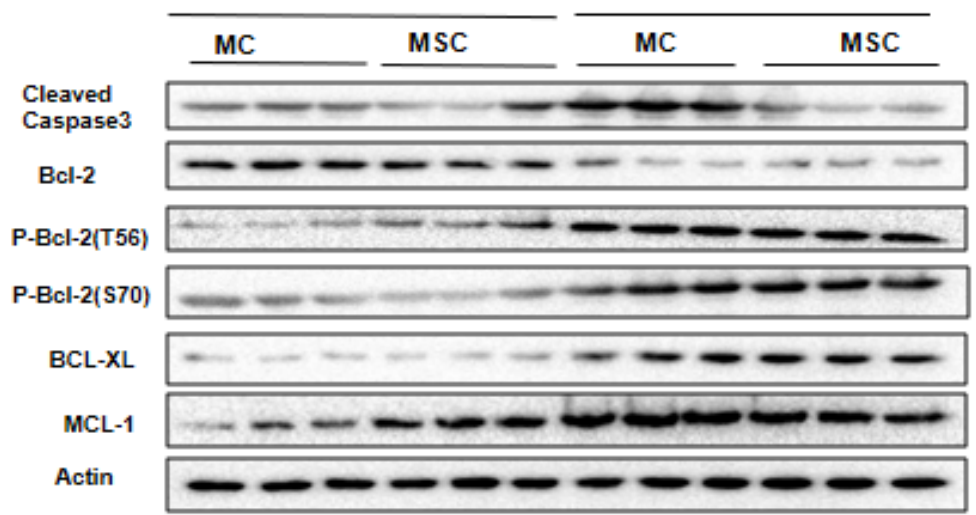

G

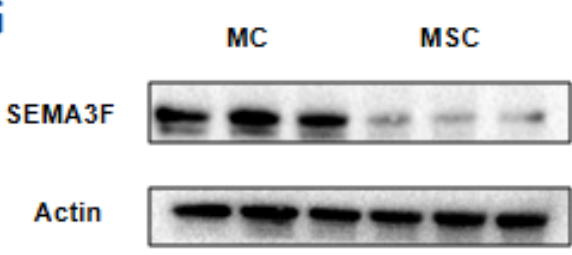

H

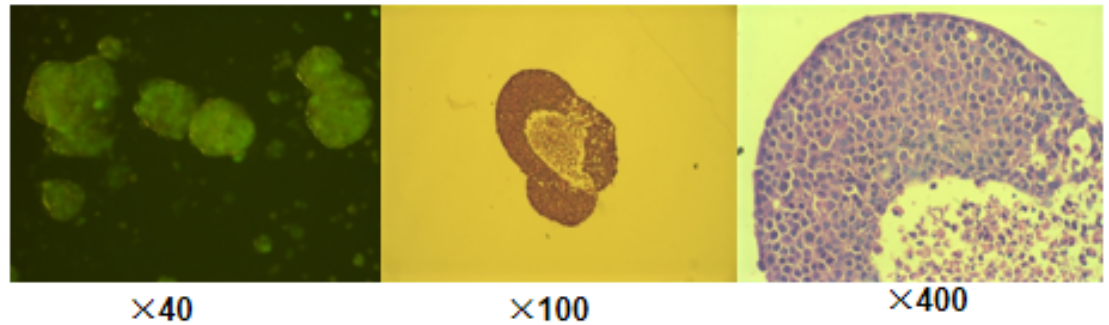

Figure 1

MSC exhibits resistance to 5-Fu.

(A) IC50 value of 5-Fu in a series of human CRC cell lines (HCT-116, LS174T, HT-29, SW480, SW620, LoVo, and RKO cells) under MSC conditions.

(B) IC50 value of 5-Fu in HT-29 cells under MSC and MC conditions. A significant difference in IC50 value was observed between the two groups $(* \star P<0.01)$. 
(C) The viability of HT-29 cells under MSC and MC conditions treated with 5-Fu at various concentrations $(10,50,100,200$ and $400 \mu \mathrm{mol} / \mathrm{L})$. Statistical analysis was performed by two-way ANOVA, and a significant difference among the groups was observed ( $\left.{ }^{\star *} P<0.01, * \star \star \star P<0.0001\right)$.

(D) The survival curve of HT-29 cells under MSC and MC conditions treated with 5 -Fu $(200 \mu \mathrm{mol} / \mathrm{L})$ for 72 h $(* \star \star \star P<0.0001)$.

(E) Flow cytometry assay to detect the apoptosis rate of HT-29 cells under MSC and MC conditions. The apoptosis rates of HT-29 cells in MC group treated with 5-Fu $(100 \mu \mathrm{mol} / \mathrm{L})$ or not were $16.55 \%$ (LR 13.65\%, UR 2.90\%) and 9.27\% (LR 9.18\%, UR 0.09\%) respectively, and in MSC group were $13.03 \%$ (LR 9.74\%, UR 3.29\%) and $11.06 \%$ (LR 7.63\%, UR 3.43\%) respectively. The experiment was repeated three times and the statistical histogram was shown. Statistical analysis was performed by two-way ANOVA, and a significant difference was observed under $M C$ conditions $\left({ }^{*} \mathrm{P}<0.01\right)$.

(F) Western blot analysis of expression of the apoptosis-related molecules MCL-1, BCL-XL, BCL-2 and cleaved caspase 3 in HT-29 cells before and after 5-Fu treatment.

(G) Western blot analysis of the expression level of SEMA3F in HT-29 cells under MSC and MC conditions.

(H)Tumor spheroids formed by three-dimensional culture. 


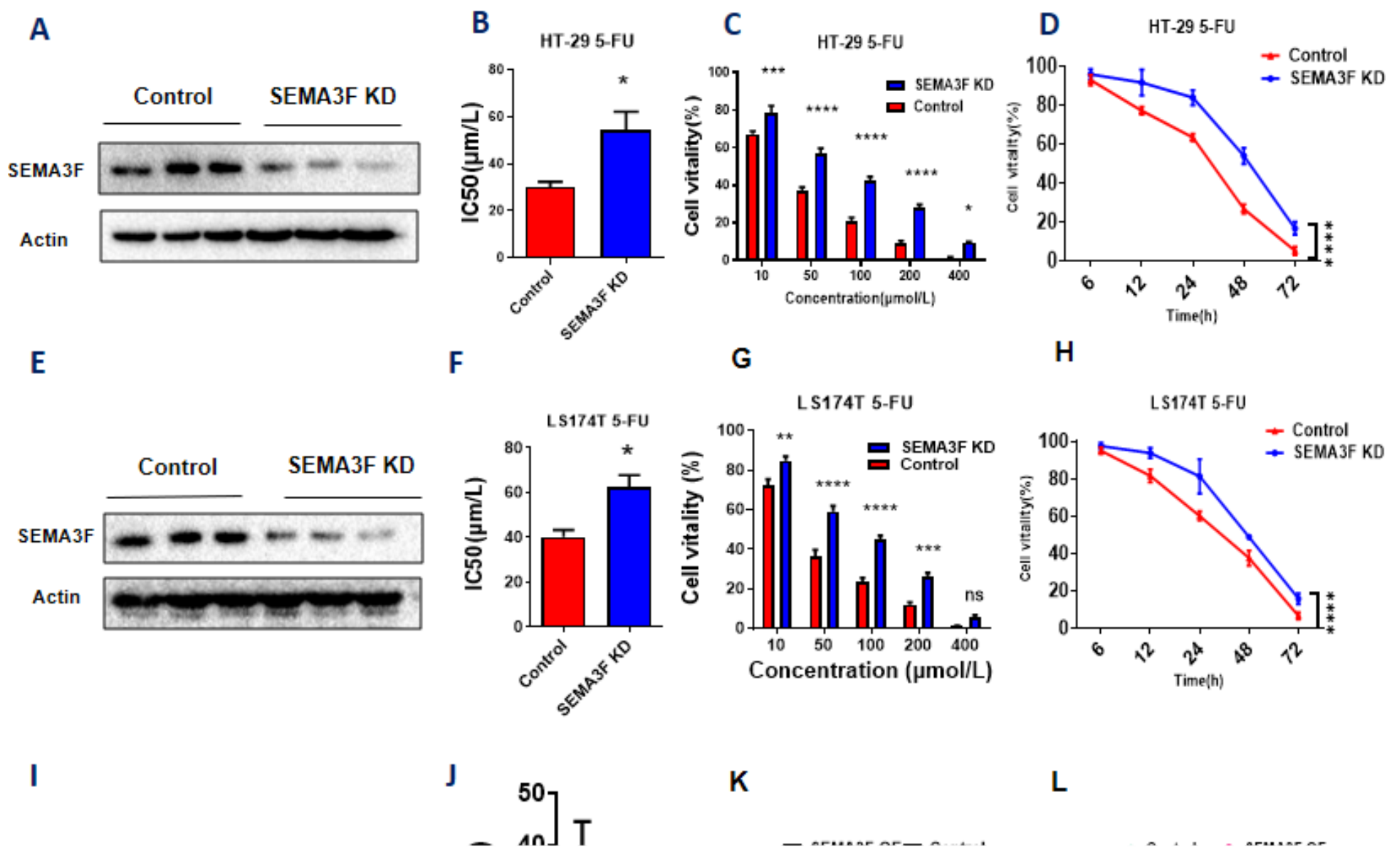

Figure 2

SEMA3F activity determines the chemotherapeutic response of CRC cells to 5-Fu in vitro.

(A) SEMA3F was knocked down in HT-29 cells.

(B) The IC50 value of 5-Fu in HT-29 cells under MSC conditions was higher in the SEMA3F KD group than in the control group $\left({ }^{*} \mathrm{P}<0.05\right)$.

(C) The viability rates of HT-29 cells with SEMA3F knockdown under MSC conditions were higher than that in the control groups upon treatment with 5-Fu at various concentrations $(10,50,100,200$ and 400 $\mu \mathrm{mol} / \mathrm{L})\left({ }^{*} \mathrm{P}<0.05,{ }^{\star *} \mathrm{P}<0.01,{ }^{* \star \star *} \mathrm{P}<0.0001\right)$. 
(D) The survival curve of HT-29 cells under MSC conditions treated with 5 -Fu for $72 \mathrm{~h}(200 \mu \mathrm{mol} / \mathrm{L})$ is shown, and HT-29 cell viability under MSC conditions was higher with SEMA3F knockdown than in the control groups $(\star \star \star \star P<0.0001)$.

(E) SEMA3F was knocked down in LS174T cells.

(F) The IC50 value of 5-Fu in LS174T cells under MSC conditions was higher in the SEMA3F KD groups than in the control groups $\left({ }^{*} \mathrm{P}<0.05\right)$.

(G) The viability of LS174T cells under MSC conditions was higher with SEMA3F knockdown than in the control groups upon treatment with 5-Fu at various concentrations (10, 50, 100, 200 and $400 \mu \mathrm{mol} / \mathrm{L})$ $\left({ }^{\star *} \mathrm{P}<0.01,{ }^{\star \star *} \mathrm{P}<0.001,{ }^{\star \star \star * *} \mathrm{P}<0.0001\right)$.

(H) The survival curve of LS174T cells under MSC conditions treated with $5-\mathrm{Fu}(200 \mu \mathrm{mol} / \mathrm{L})$ for $72 \mathrm{~h}$ is shown. LS174T cell viability under MSC conditions was higher with SEMA3F knockdown than in the control groups $(\star \star \star \star P<0.0001)$.

(I) SEMA3F was overexpressed in LoVo cells.

(J) The IC50 value of 5-Fu in LoVo cells under MSC conditions was lower in the SEMA3F OE group than in the control groups $\left({ }^{*} \mathrm{P}<0.05\right)$.

(K) The viability of LoVo cells with SEMA3F overexpression under MSC conditions was lower than that in the control groups upon treatment with 5 -Fu at various concentrations $(10,50,100,200$ and $400 \mu \mathrm{mol} / \mathrm{L})$ $(\star \star P<0.01, * \star * P<0.001, * \star \star * P<0.0001)$.

(L) The survival curve of LoVo cells under MSC conditions treated with 5 -Fu $(200 \mu \mathrm{mol} / \mathrm{L})$ for $72 \mathrm{~h}$ is shown. The vitality of LoVo cells with SEMA3F OE under MSC conditions was lower than that in the control groups $(* * \mathrm{P}<0.01)$. 
A Control

$5-\mathrm{FU}$
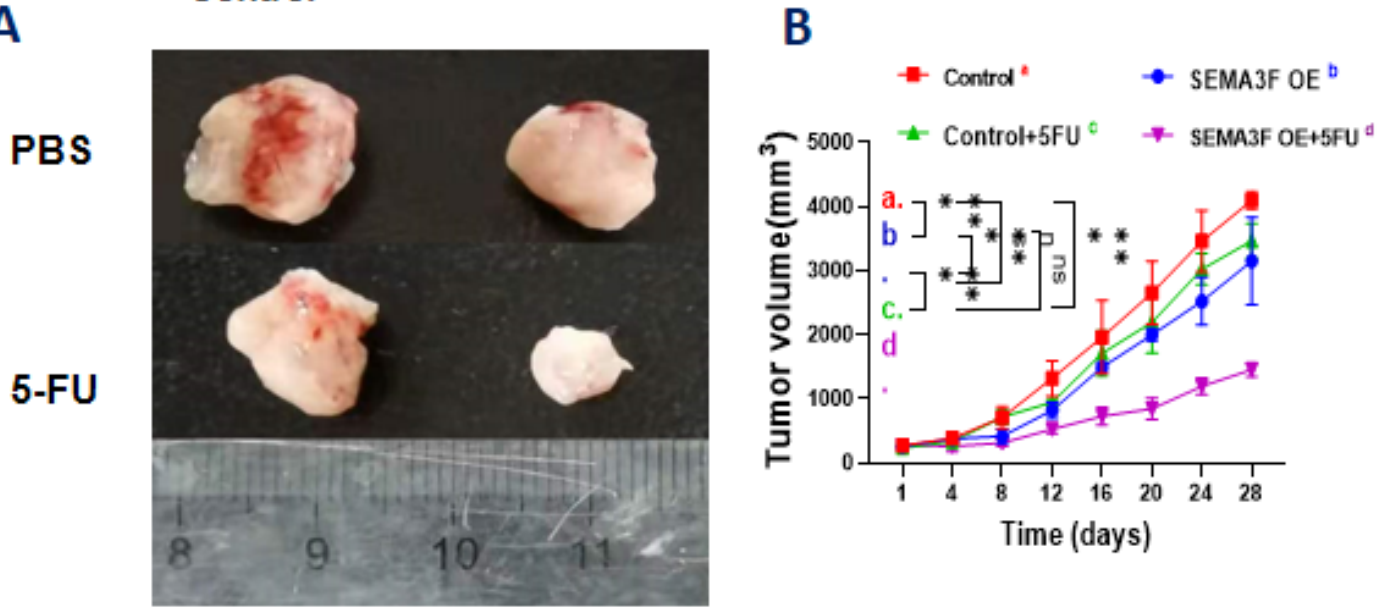

C

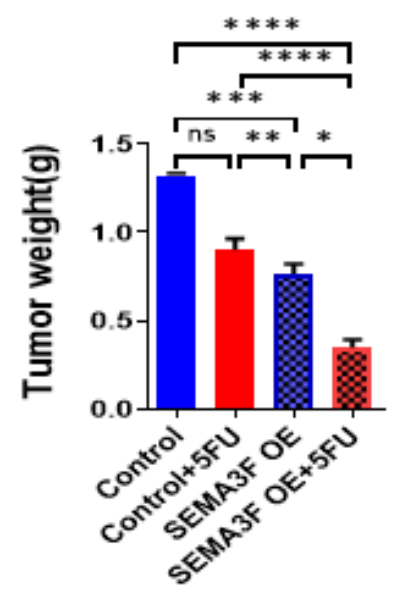

\section{Caspase 3}
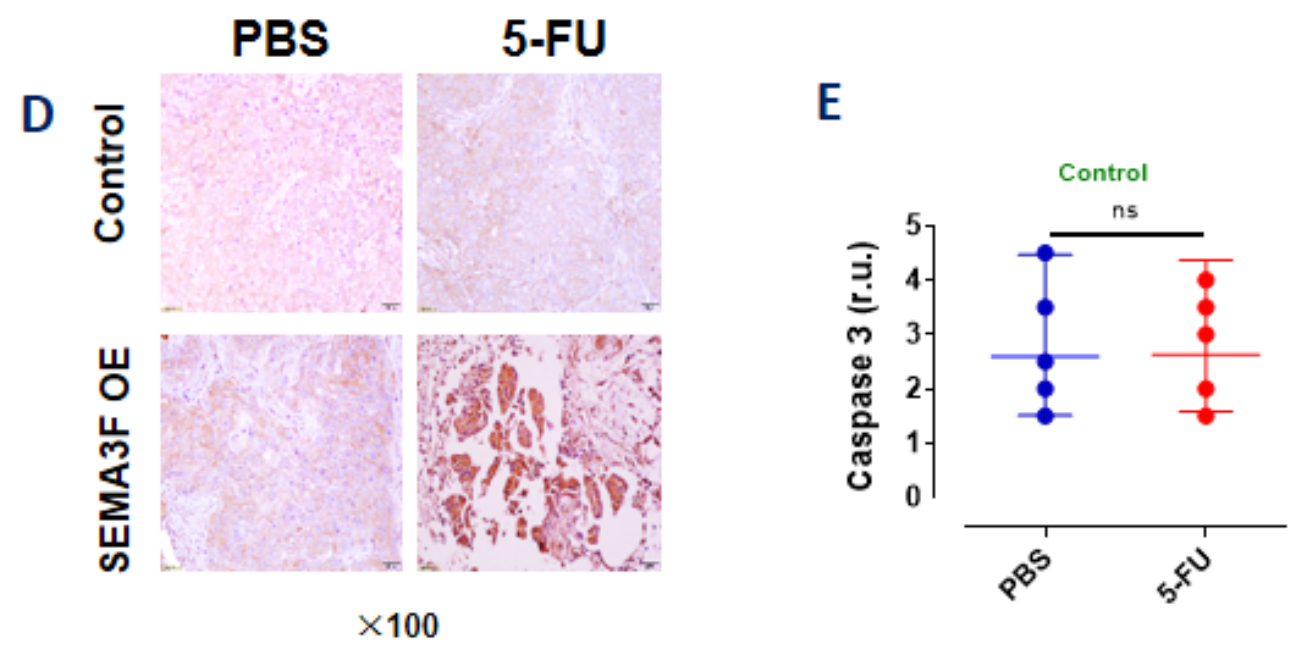

SEMA $3 F$ OE

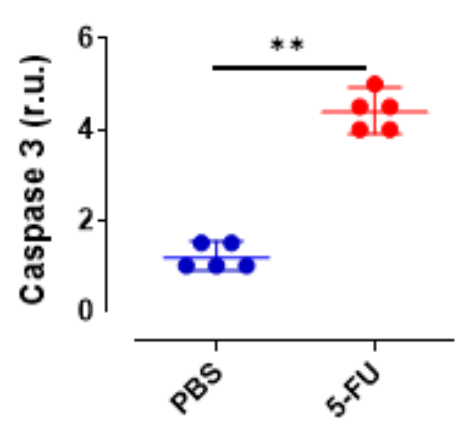

\section{Figure 3}

SEMA3F overexpression enhanced the sensitivity of CRC cells to 5-Fu in vivo.

(A) Mice were subcutaneously injected with LoVo cells (SEMA3F OE LoVo cells for the test groups, LoVo cells for the control groups) in the left groin. Changes in the volume of tumor xenografts in the SEMA3F OE groups and the control groups treated with 5-Fu or PBS were determined.

(B-C) Statistical analysis of tumor volume and weight in the SEMA3F OE groups and control groups before and after 5 -Fu treatment $\left({ }^{\star} P<0.05,{ }^{*} P<<0.01,{ }^{*} * * P<0.001,{ }^{*} * \star * P<0.0001\right)$.

(D) Immunohistochemical staining of caspase3 in CRC tissues from the SEMA3F OE groups and control groups treated with 5-Fu or PBS. 
(E) Statistical analysis of caspase3 in CRC tissues from the SEMA3F OE groups and control groups treated with 5-Fu or PBS $\left({ }^{*} \mathrm{P}<0.01\right)$.

A

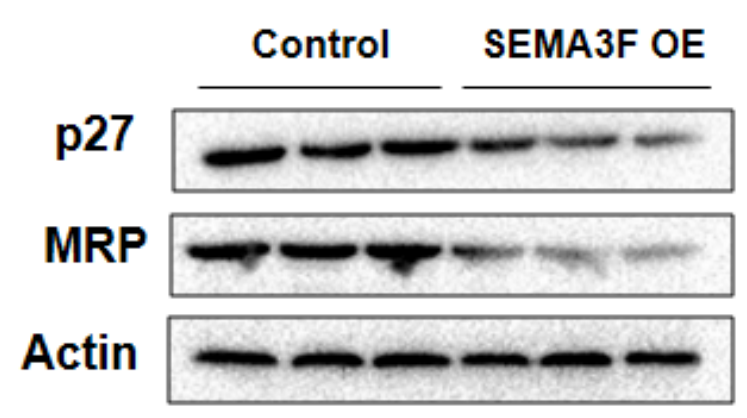

B
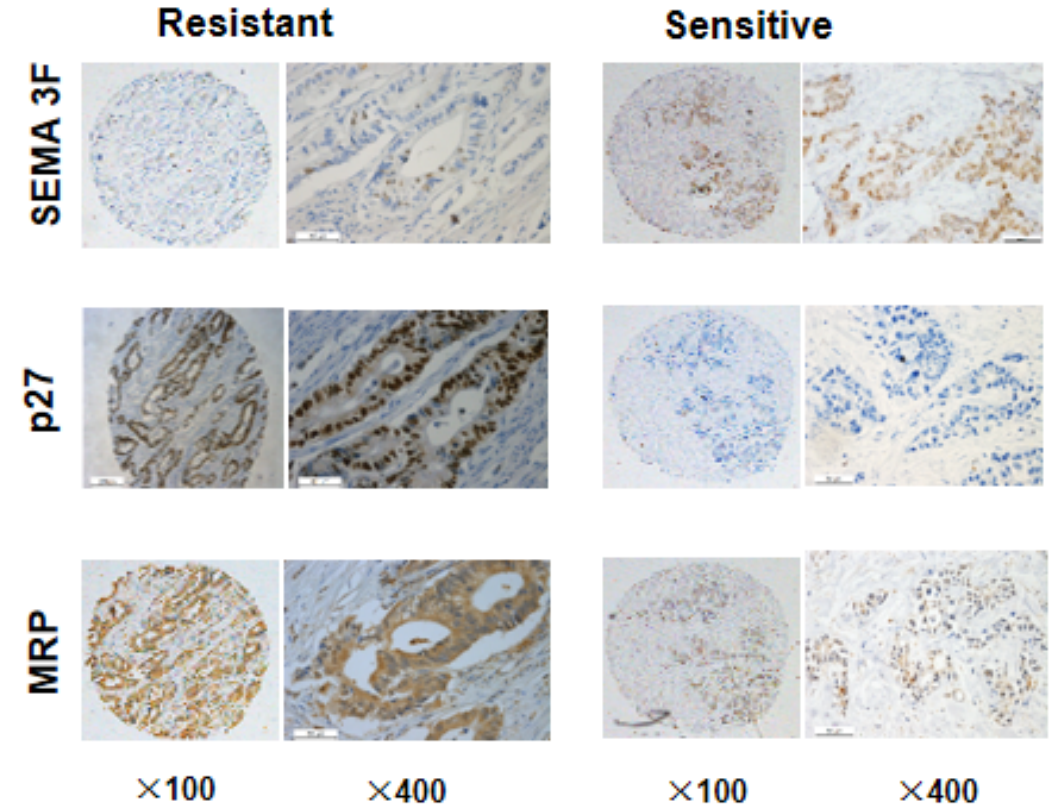

D
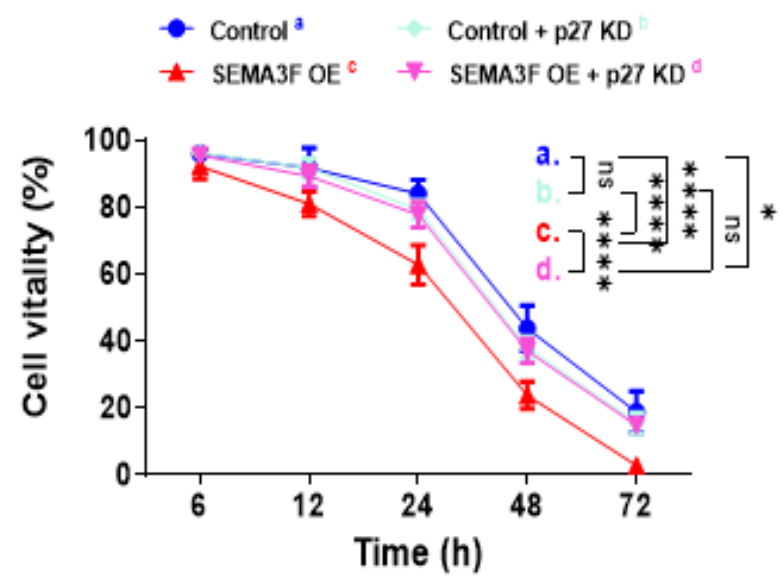

Figure 4

SEMA3F enhances the chemotherapeutic sensitivity of CRC cells to 5-Fu by downregulating p27.

(A) Western blotting was used to assess the nuclear expression levels of p27 and MRP in the SEMA3F OE and control groups.

(B) Immunohistochemical staining of SEMA3F, p27 and MRP in CRC patient tissues sensitive and resistant to chemotherapy. 
(C) The viability rates of LoVo cells with different expression levels of p27 and SEMA3F after treatment with 5-Fu at various concentrations $(10,50,100,200$ and $400 \mu \mathrm{mol} / \mathrm{L})$ are shown ( $\left.{ }^{* \star \star *} \mathrm{P}<0.0001\right)$.

(D) The survival curves of LoVo cells expressing different levels of p27 and SEMA3F after treatment with 5 -Fu $(200 \mu \mathrm{mol} / \mathrm{L})$ for $72 \mathrm{~h}$ are shown $\left({ }^{*} P<0.05\right.$, $\left.{ }^{\star \star \star *} P<0.0001\right)$.

A
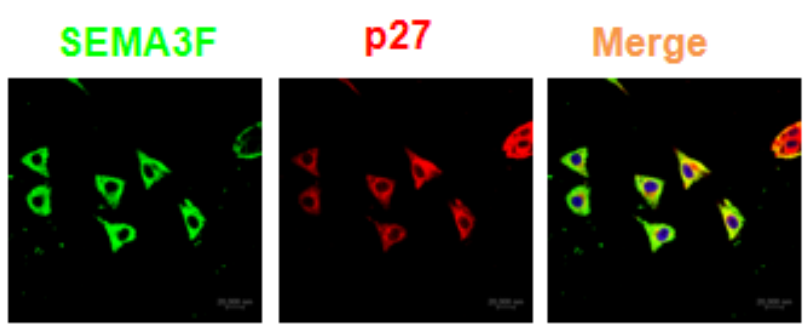

C

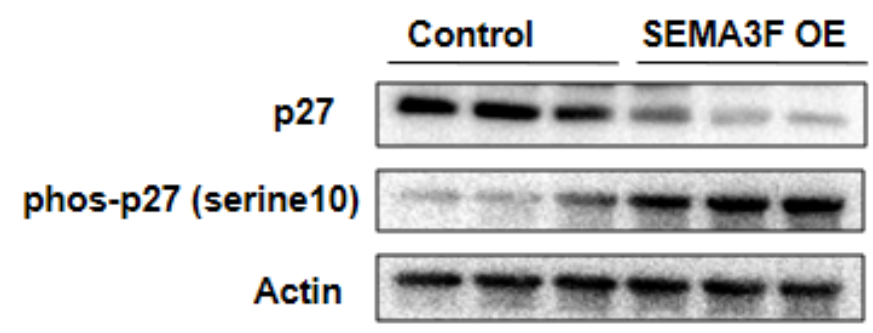

B

IP: SEMA3F

IB: p27

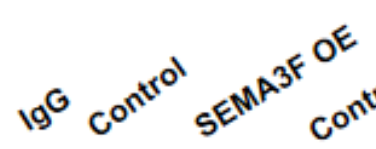

se

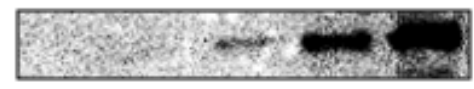

\section{Figure 5}

SEMA3F promotes p27 degradation by interacting with p27 and inducing its phosphorylation at Ser10.

(A) Immunofluorescence analysis of SEMA3F (green) and p27 (red) in LoVo cells with SEMA3F OE.

(B) The interaction between SEMA3F and p27 was assessed using an immunoprecipitation assay with LoVo cells with SEMA3F OE.

(C) p27 and phosphorylated p27 expression levels in LoVo cells with SEMA3F OE and control cells were determined by Western blot analysis.

(D) Western blot analysis was used to determine SEMA3F and p27 expression levels in the SEMA3F OE and control groups when the phosphorylation of p27 was or was not inhibited. 
A
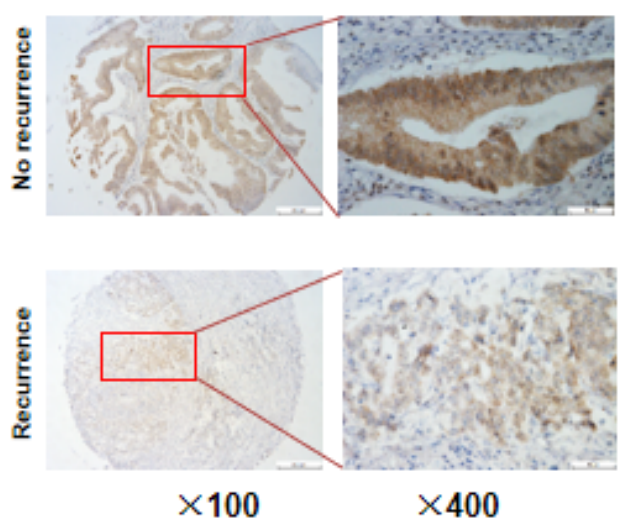

C

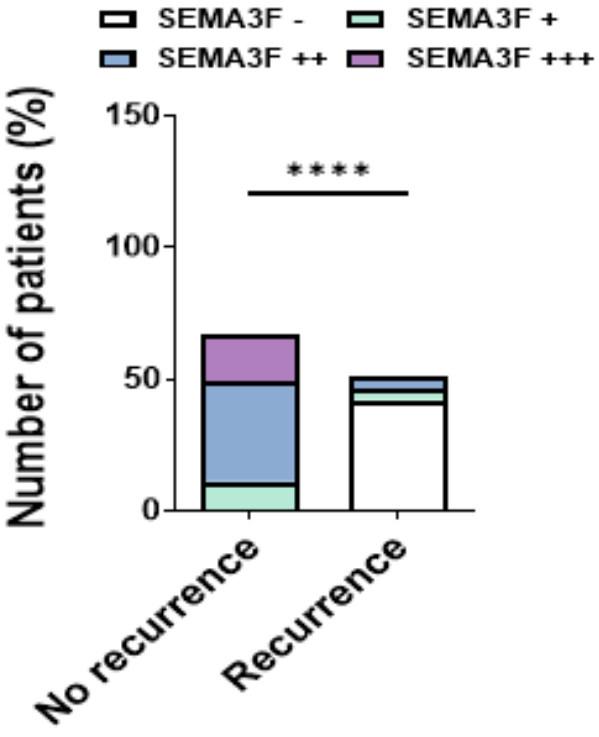

B

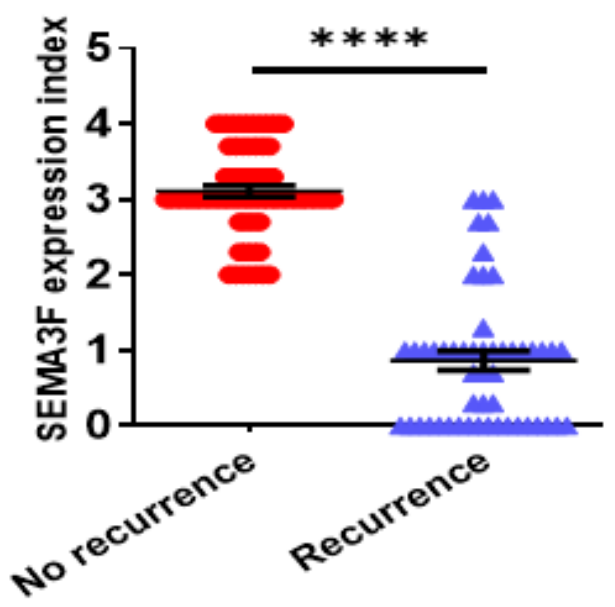

D

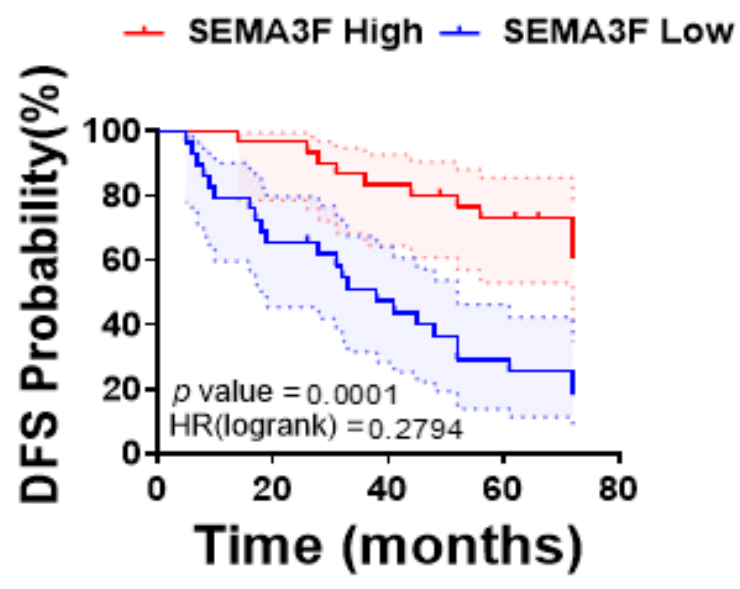

Figure 6

CRC patients with high SEMA3F expression are more sensitive to 5-Fu chemotherapy than patients with low expression.

(A) Immunohistochemical staining of SEMA3F was carried out in tissues from patients with recurrent CRC and patients with no recurrence.

(B) The SEMA3F expression indexes in the recurrence and no recurrence groups are shown $(* \star * * \mathrm{P}<0.0001)$.

(C) Statistical analysis of immunohistochemical staining data for SEMA3F in patients with recurrent and nonrecurrent CRC $(* \star \star \star P<0.0001)$.

(D) Statistical analysis of 6-year disease-free survival in patients with high SEMA3F expression and low SEMA3F expression (HR=0.28, 95\% Cl: 0.14-0.56, $\mathrm{P}=0.0001)$. 